\title{
PRECEDENTES JUDICIAIS E ACESSO À JUSTIÇA: ARGUMENTOS FAVORÁVEIS À SUA UTILIZAÇÃO
}

\author{
Bernardo Augusto da Costa Pereira ${ }^{1}$
}

Resumo:

O presente artigo realiza uma análise acerca de seis argumentos favoráveis ao uso dos precedentes judiciais como forma de alcançar um efetivo acesso à justiça: segurança jurídica, igualdade, coerência, definição de expectativas, celeridade processual e economia argumentativa. Primeiramente se verifica a importância dos precedentes para uma melhor prestação jurisdicional. Em seguida os argumentos supracitados são desenvolvidos e relacionados. Para embasar este estudo foi utilizada moderna doutrina estrangeira e nacional. Conclui-se que o adequado uso dos precedentes judiciais é capaz de fortalecer e aprimorar a prática jurídica brasileira.

Palavras chave: Acesso à justiça; precedentes judiciais; segurança jurídica; igualdade; celeridade processual;

\section{JUDICIAL PRECEDENTS AND ACCESS TO JUSTICE: FAVORABLE ARGUMENTS TO THEIR USE}

\section{Abstract:}

This article analyzes six arguments in favor of using judicial precedents as a way to achieve effective access to justice: legal certainty, equality, coherence, definition of expectations, procedural speed and argumentative economy. Firstly, the importance of precedents for a better judicial performance is verified. Then the arguments above are developed and related. To support this study, modern foreign and national doctrine was used. It is concluded that the appropriate use of judicial precedents is capable of strengthening and improving Brazilian legal practice.

Key words: Access to justice; judicial precedents; legal certainty; equality; procedural speed;

\section{INTRODUÇÃO}

\footnotetext{
${ }^{1}$ Doutorando em Direito pela Universidade Federal do Pará - UFPA. Professor dos cursos de Direito do Centro Universitário do Estado do Pará - CESUPA e da Faculdade Ideal - FACI. Advogado. Endereço eletrônico: bapbernardo@gmail.com.
} 
O presente estudo surgiu em virtude da importância de analisar o acesso à justiça e sua relação com os precedentes judiciais. Inicia-se tratando da importância destes dois temas, atualmente em voga tanto do ponto de vista teórico como prático. Pontua-se a chamada "Crise do Judiciário" e sua relação com o fortalecimento dos precedentes, o que se verifica facilmente com o atual código de processo civil.

Com esta base, estudam-se argumentos favoráveis ao uso dos precedentes judicias, defendendo que, caso estes sejam bem utilizados, o potencial de ganho para o sistema jurídico brasileiro é real. Segurança jurídica, igualdade, coerência, definição de expectativas, celeridade processual e economia argumentativa são analisadas.

O objetivo geral deste trabalho, portanto, é analisar de que forma os precedentes judiciais se relacionam com o acesso à justiça.

Por sua vez, o objetivo específico é analisar os argumentos da segurança jurídica, igualdade, coerência, definição de expectativas, celeridade processual e economia argumentativa, e como eles podem contribuir para o fortalecimento de uma atividade jurisdicional mais adequada, capaz de respeitar o princípio constitucional brasileiro de acesso à ordem jurídica justa.

Para corroborar o presente artigo foi utilizada moderna doutrina, estrangeira e nacional, bem como precedentes judiciais relevantes. Pretende-se, assim, que este estudo venha a auxiliar a comunidade acadêmica ao tratar de tema de tão grande relevância no atual cenário jurídico brasileiro.

\section{A IMPORTÂNCIA DOS PRECEDENTES JUDICIAIS E O ACESSO À JUSTIÇA}

Diversos são os obstáculos ao alcance de um efetivo acesso à justiça. Os custos do processo, o valor dos honorários advocatícios, a orientação jurídica inadequada, a necessidade de ampliação de reconhecimento de direitos coletivos lato sensu, a demora excessiva para o julgamento das lides, a disparidade entre os grandes litigantes e os litigantes eventuais, além do formalismo exacerbado, são alguns dos elementos que impedem um acesso à justiça efetivo.

Com o passar do tempo, diversos mecanismos foram criados para minorar os males de um acesso à justiça ineficiente. Cappelleti e Garth (2002, p. 31) tratam de três "ondas" de acesso à justiça, as quais emergiram mais ou menos em ordem cronológica, a partir de 1965: a 
primeira "onda" foi a da assistência judiciária, a segunda trata da representação jurídica para direitos difusos (ambiental e do consumidor, por exemplo) e a terceira, denominada, de "enfoque de acesso à justiça" inclui os posicionamentos prévios, mas reconhece a necessidade de maior esforço articulado para superar os entraves próprios ao acesso à justiça.

A chamada "Crise do Judiciário" surgiu devido à incapacidade deste de julgar em tempo hábil todas as demandas a ele submetidas. O grande número de demandas, a grande quantidade de recursos, as dificuldades na fase/processo de execução, além da presença constante dos chamados "grandes litigantes", tais quais bancos e o próprio Estado, impediam (e ainda impedem) o Poder Judiciário, com seus poucos profissionais, de solucionar todas as crises apresentadas em tempo adequado. Trata-se de crise tanto interna, pelos motivos supracitados, como externa, uma vez que a demora da prestação jurisdicional leva a sociedade a um estado de descrença.

Visando superá-la, aprovou-se a Emenda Constitucional n. 45/2004 que buscava acelerar a solução das lides apresentadas ao Poder Judiciário, incluindo o inciso LXXVIII, ao art. $5^{\circ}$ da Constituição brasileira (BRASIL, 1988), instituindo expressamente o princípio da razoável duração do processo como cláusula pétrea.

No Brasil, a preocupação com a tempestividade da resposta jurisdicional direcionou a atividade legislativa a criar meios para garantir um processo sem dilações indevidas, tais como o estabelecimento de diversos ritos e adequações procedimentais, a valorização das decisões de tribunais superiores, a ampliação dos poderes dos relatores, entre outros (BASTOS, 2012, p. 82-83).

A ampliação de técnicas de vinculação de decisões judiciais baseadas em precedentes é uma outra forma de tentar alcançar a prestação jurisdicional adequada, célere e efetiva, garantida pela norma constitucional. José Henrique Mouta Araújo (2010, p. 56) aponta que a ampliação da verticalização e horizontalização das decisões dos Tribunais Superiores em causas repetitivas está fortemente relacionada a preocupação dos efeitos nocivos do tempo no processo, especialmente nas últimas reformas processuais.

O próprio Código de Processo Civil de 2015 surge com esta visão. Ao criar institutos como o Incidente de Resolução de Demandas Repetitivas (IRDR) e o Incidente de Assunção de Competência (IAC), bem como tratar explicitamente dos precedentes judiciais em diversas passagens, isso fica cristalino.

Revista Cidadania e Acesso à Justiça | e-ISSN: 2526-026X | Encontro Virtual | v. 6 | n. 2 | p. 18 35 | Jul/Dez. 2020. 
Todavia, para que tais alterações alcancem seus escopos, é necessário compreender os precedentes judiciais não apenas como mecanismos de autoridade judicial, visando apenas a celeridade das decisões. A qualidade do precedente precisa ser prestigiada, sob pena de infringir o devido processo legal e o próprio acesso efetivo à justiça. Neste caso, a razoável duração do processo será pouco relevante, vez que o próprio processo foi malversado.

\section{ARGUMENTOS FAVORÁVEIS AO USO DOS PRECEDENTES JUDICIAIS}

Diversos são os argumentos que advogam pela adoção de uma cultura de precedentes judiciais, seja no Brasil, seja em outros países. Neste trabalho tratar-se-á da igualdade, da segurança jurídica, da definição de expectativas e da celeridade processual. Mas antes disto, é preciso deixar algo claro, e, que muitas vezes, passa despercebido.

Tais argumentos são utilizados para justificar o uso de precedentes judiciais, mas não podem ser considerados dissociados destes: tais objetivos só serão alcançados com o bom manejo dos precedentes. Entende-se que o precedente deve ser concebido como um instrumento hermenêutico, capaz de gerar ganhos interpretativos ao ser utilizado, pois permite o diálogo entre as decisões passadas com os julgadores do presente (PEREIRA, 2017, p. 59). Esta noção precisa ser considerada, pois, caso se vislumbre o precedente apenas no seu viés autoritário, as mesmas deficiências que a lei enfrenta serão óbice ao seu sucesso.

A lei não é precedente judicial, logo não pode ser aplicada da mesma forma. Tradicionalmente, a lei também seria capaz de gerar igualdade, coerência, segurança jurídica, celeridade, previsibilidade, entre outros elementos. Mas exatamente por não ser capaz de alcançá-los em níveis desejados, o precedente ganha importância em países enquadrados na tradição do civil law, como no Brasil.

Caso não se considere o precedente como uma forma de ampliar o debate, através de sua característica dialética, os argumentos a seguir expostos não serão alcançados. Eles são consequências da aplicação adequada do precedente judicial; por conseguinte, caso não seja bem aplicado, também restarão prejudicados.

Não haverá adequada celeridade processual, definição de expectativas, coerência, igualdade, ou qualquer dos outros aspectos a seguir delineados, caso o precedente seja incorretamente manejado. 
Por fim, é importante ressaltar que apesar de separados em subtópicos, tais temas estão profundamente interligados, de maneira que sua análise não deve ser realizada de forma isolada.

\subsection{SEGURANÇA JURÍDICA, IGUALDADE E COERÊNCIA}

É indubitável a importância da segurança jurídica para um Estado Democrático de Direito. Independente do país e da tradição jurídica, esta segurança é considerada um elemento base do ordenamento, que permite a previsibilidade das normas jurídicas e a estabilidade das decisões judiciais. A previsibilidade e a estabilidade, pois, são elementos marcantes desta segurança jurídica.

Em países de tradição romano-germânica a previsibilidade de suas normas advém da legislação, enquanto que em países de common law, os precedentes judiciais se encarregam, ao menos tradicionalmente, de alcançar esta segurança. Trata-se de valor muito caro a ambas as famílias jurídicas. Ainda assim, atualmente, com a aproximação dos sistemas jurídicos esta distinção se torna cada vez menos real.

A importância em tornar o direito previsível é grande especialmente para o cidadão, que, devido a ela, pode tanto planejar suas ações, como ter a certeza de que não terá seus direitos violados. Neste sentido, Marinoni (2011, p. 122) afirma que:

O cidadão precisa ter segurança de que o Estado e os terceiros se comportarão de acordo com o direito e de que os órgãos incumbidos de aplicá-lo o farão valer quando desrespeitado. Por outro lado, a segurança jurídica também importa para que o cidadão possa definir o seu próprio comportamento e as suas ações. O primeiro aspecto demonstra que se trata de garantia em relação ao comportamento daqueles que podem contestar o direito e têm o de dever de aplicá-lo; o segundo quer dizer que ela é indispensável para que o cidadão possa definir o modo de ser das suas atividades.

No Brasil, a Constituição da República considera tanto a igualdade como a segurança valores fundamentais, ao incluí-las, em seu art. $5^{\circ}$, caput, juntamente com a vida, a liberdade e a propriedade (BRASIL, 1988). Apesar de não tratar expressamente da segurança jurídica, esta é vislumbrada quando a Carta Magna brasileira se refere ao direito adquirido, ao ato jurídico perfeito e à coisa julgada.

\section{Revista Cidadania e Acesso à Justiça | e-ISSN: 2526-026X | Encontro Virtual | v. 6 | n. 2 | p. 18 -} 35 | Jul/Dez. 2020. 
Ao tratar de precedentes, a igualdade e a segurança podem ser vistas como a certeza de que determinada decisão será seguida de forma reiterada, em casos similares. E de fato, a doutrina do stare decisis prega que casos similares tenham decisões similares, mas a questão não se exaure apenas com isto.

Sem dúvida, a aplicação de um entendimento jurisprudencial de uma corte superior permite que haja segurança jurídica, no sentido acima tratado. Mas caso a análise dos elementos constituintes do precedente judicial, quais sejam ratio decidendi e obiter dictum, seja feita erroneamente, os prejuízos serão ainda maiores, vez que além de uma decisão errônea, ter-se-á um precedente para casos futuros.

Observe-se a seguinte lição de Marinoni (2011, p. 126):

Curioso é que o direito legislado, ao contrário de constituir um pressuposto, representa um obstáculo para a segurança jurídica. Isso se dá não apenas em razão da hiperinflação legislativa ou em virtude de ser impossível o pleno conhecimento das regras legais, mas substancialmente porque o sistema de direito legislado não liga a previsibilidade e a confiança a quem define o que é o direito.

O autor explicitamente defende que a questão da incapacidade da lei não alcançar a segurança jurídica se deve ao fato dela não ser produção judiciária. Ou seja, a segurança advém da interpretação da lei, e não da lei propriamente dita. Uma vez que a lei pode ter diversas interpretações, a segurança só é alcançada quando o Judiciário determina seu alcance no caso concreto. Trata-se de uma defesa da autoridade do precedente judicial.

Seguindo esta linha de raciocínio, quanto mais alto se encontrar o tribunal que definir o alcance da norma, em dada estrutura organizacional, melhor será para a segurança jurídica, já que seu precedente terá maior vinculatividade.

Já foi afirmado neste estudo, que isto por si só, não basta. Não existe segurança jurídica se o precedente for mal interpretado e aplicado. Neste caso, haverá uma decisão, cuja norma não se coaduna com o substrato fático. Estar-se-á trocando um problema, por outro.

Não se pode negar que existem casos, especialmente em demandas repetitivas, em que é simples aplicar um precedente, pois a tese jurídica será reaplicada em um contexto praticamente igual a aquele em que o precedente surgiu. Mas existem outros casos, em que esta aplicação é muito mais difícil. E aceitar a aplicação inadequada de um precedente, simplesmente por ser ligeiramente semelhante ao caso em análise, e por ser oriundo de um 
tribunal hierarquicamente superior é um verdadeiro risco. Esta prática não permitirá alcançar a segurança jurídica tão almejada.

A segurança que deve ser buscada não é a certeza da aplicação de um pronunciamento de um tribunal superior, e sim, a certeza de que os precedentes serão considerados na argumentação jurídica, e ainda, mais, que serão devidamente explicadas as razões para sua aplicação, ou não. É a mesma linha de pensamento de Juraci Lopes Filho (2014, p. 322):

\begin{abstract}
A segurança que se pode esperar e exigir é que o juiz sempre considere os precedentes e argumente detalhadamente por que o segue ou não, justificando por que sua decisão é a correta. A expectativa de que se repita o entendimento é, pois, um a priori, que para se confirmar ou não deve haver explicado o motivo. Se não for aplicado o precedente, deverá ser indicada a distinção essencial do jogo de-e-para presente em relação o passado. Também deverá ser justificado porque se aplica um precedente a casos distintos daqueles que deram ensejo ao caso-paradigma. Nesses termos, previsibilidade situa-se, no primeiro momento, possível de ser chamada préinterpretativa, mas sua confirmação ou rejeição depene de motivação suficiente.
\end{abstract}

A segurança jurídica e a previsibilidade não podem ser ligadas unicamente à hierarquia jurisdicional. Isto, por si só, desconsidera a importância de diversos tribunais e das cortes de primeira instância, que também contribuem para o ganho hermenêutico do direito.

Um fator que permite afirmar a previsibilidade dos precedentes é o conhecimento destas decisões judiciais, o que ocorre, principalmente, através do acesso aos sítios eletrônicos dos tribunais, os quais permitem a pesquisa livre de seus pronunciamentos judiciais, o que também gera expectativa. Todo tribunal merece ter suas decisões respeitadas, e isso passa pela análise de sua fundamentação pela corte que reanalisa o caso.

Uma vez que no direito brasileiro as cortes de $1^{\circ}$ grau analisam as provas, e tem um contato mais direto com as partes envolvidas, sua argumentação não pode ser desconsiderada, especialmente no tocante a delimitação dos aspectos próprios do caso concreto. Não considerar sua fundamentação decisória, significa, no mínimo, não levar em conta elementos essenciais para a determinação dos contornos fáticos e a consequente escolha do precedente judicial a ser aplicado ou rejeitado.

Outro aspecto vital para alcançar a segurança jurídica é a estabilidade de normas aplicáveis e consequentemente da interpretação destas normas. A estabilidade pode ser 
alcançada com a obediência hierárquica dos precedentes. Contudo, muito mais estável, e nesse sentido, estável tanto do ponto de vista de decisões iguais, como na certeza de um efetivo diálogo entre o caso precedente e o caso presente, é a decisão judicial que foi devidamente analisada e debatida.

A igualdade que se busca com o uso dos precedentes, portanto, não é a mera reaplicação de decisão prévia em um novo caso. Isto nada mais é do que aplicar a lei no caso atual, da mesma forma que foi aplicada anteriormente. Isso é isonomia legal.

Ao se buscar isonomia na aplicação de precedentes, os elementos para essa aproximação devem ser do próprio precedente, e não da lei que foi usada no caso paradigma (aproximação indireta). Com base em uma teoria do precedente com viés hermenêutico, a lei é apenas um dos fatores que influenciaram o precedente. A igualdade buscada deve ser na resposta institucional, ou seja, em situações similares, o Judiciário precisa levar em consideração os argumentos jurídicos que fundamentam o caso anterior. É por isso que se pode aceitar, por exemplo, que um princípio jurídico aplicado em uma esfera jurídica, possa ser usado para fundamentar um caso de outro ramo do direito (LOPES FILHO, 2014, p. 360).

\subsection{DEFINIÇÃO DE EXPECTATIVAS: DESESTIMULO À LITIGÂNCIA E FAVORECIMENTO DE ACORDOS}

Antes mesmo de ingressar com uma demanda judicial, já existem expectativas em jogo. A importância da previsibilidade, anteriormente tratada, se reflete fortemente nestas expectativas. Ao saber que sua pretensão não será judicialmente acolhida, o indivíduo, de antemão, evitará a propositura da demanda.

Yeon-Koo Che e Jong Goo Yi (1993, p. 418) afirmam que: "Since an initial court decision has long-term effects, it still remains true that the repeat player will try to avoid litigation whenever an unfavorable precedent is likely to be set in an early stage".2.

No mesmo sentido, Jean Carlos Dias (2009, p. 100):

Quando o cenário é transformado, isto é, quando passamos a um modelo institucional em que as decisões judiciais tendem a uma maior

\footnotetext{
2 "Uma vez que a decisão de uma corte inicial tem efeitos em longo prazo, continua sendo verdade que o litigante habitual vai tentar evitar a litigância sempre que um precedente desfavorável provavelmente vier a ser definido em um estágio inicial". Traduzido pelo autor.
} 
uniformidade, o efeito óbvio é que a informação a respeito do valor da pretensão/resistência torna-se mais claramente perceptível e, com isso fica facilitado o juízo de revisão de expectativas.

A aplicação dos precedentes, desta forma, permite ao jurisdicionado condições mais efetivas de prever o desfecho de seu caso. Desta maneira, pode-se agir de forma a maximizar os lucros e minimizar os prejuízos, com base em uma análise econômica do direito. Isto reflete, imediatamente, na abstenção de proposituras de novas demandas e na ampliação de acordos.

Neste último caso, por mais que a parte possua um precedente a seu favor, pode não ser benéfico continuar a relação jurídica processual, dado o desgaste financeiro, e emocional, além do lapso temporal até o seu encerramento. O acordo, assim, passa a ter também parâmetros financeiros, já que existe uma condenação prévia em valor específico. Conforme leciona Marinoni (2011, p. 183):

É certo que a previsibilidade da decisão a ser dada ao litígio, à primeira vista, beneficia uma parte em detrimento da outra. Ou seja, é possível pensar que a parte em cujo favor o precedente milita pode ser estimulada a litigar. No entanto, a previsibilidade permite às duas partes a racionalização das vantagens e desvantagens da litigiosidade. Naturalmente, a parte cuja pretensão está de acordo com o precedente tem vantagem sobre a outra, já que em seu desfavor operam apenas a demora e os custos do processo. Não obstante, a parte que sabe que provavelmente terá decisão contrária sentirse-á propensa a evitar o litígio, oferecendo vantagens que sejam capazes de desestimular o seu oponente de propor a ação. Quer isso precisamente dizer que a previsibilidade acomoda a situação de conflito, desestimulando ambos o litigantes de contender e favorecendo os acordos.

Da mesma forma, mas mais lentamente, é possível alterar o padrão de comportamento da pessoa física ou jurídica. Ao se ter condições de presumir o desfecho judicial negativo de uma demanda, os envolvidos, e neste caso, especialmente os litigantes habituais, alteram seus comportamentos para evitar futuras condenações.

Todavia, para se alcançar esta previsibilidade e consequentemente racionalização de expectativas é essencial conhecer os precedentes judiciais, o que ocorre, principalmente, através do acesso aos sítios eletrônicos dos tribunais, os quais permitem a pesquisa livre de seus pronunciamentos.

Revista Cidadania e Acesso à Justiça | e-ISSN: 2526-026X | Encontro Virtual | v. 6 | n. 2 | p. 18 35 | Jul/Dez. 2020. 
E neste caso, é importante saber qual precedente possui maior força, não apenas em virtude da corte que proferiu, mas sim pelo debate e desenvolvimento da decisão pretérita. Todas as cortes possuem posicionamentos e isto gera expectativa. A dificuldade ocorre quando as cortes mais relevantes, hierarquicamente falando, possuem posições divergentes.

No caso brasileiro, duas cortes chamam a atenção. O Supremo Tribunal Federal e o Superior Tribunal de Justiça. A primeira tem a função primordial de interpretar a Constituição do Brasil, enquanto que o STJ visa uniformizar a interpretação infraconstitucional. Tratam-se de dois tribunais que frequentemente são citados pelas cortes inferiores, e consequentemente, possuem seus precedentes constantemente analisados e aplicados.

Ocorre que tais tribunais também possuem posicionamentos divergentes entre si, em algumas situações, o que dificulta sobremaneira a definição das expectativas dos envolvidos. É o que ocorreu em dissidência jurisprudencial acerca da isenção de COFINS (Contribuição para Financiamento da Seguridade Social) para sociedades civis prestadoras de serviço, a qual foi instituída pela lei complementar n. 70/1991, e revogada pela lei ordinária n. 9.430/96.

A discussão se pautava acerca da hierarquia entre as leis complementar e ordinária, supracitadas, de modo que a discussão era exclusivamente jurídica, e não fática. O STJ analisou a matéria e depois de reiteradas discussões e pacificação de sua jurisprudência, exarou a súmula 276/STJ, no ano de 2003, que determinava que: "as sociedades civis de prestação de serviços profissionais são isentas da COFINS, irrelevante o regime tributário adotado".

A matéria veio a ser discutida pelo Supremo Tribunal Federal, em 2008, no julgamento do Recurso Extraordinário n. $377.457^{3}$. A Corte decidiu pela inexistência hierárquica entre a lei complementar e a lei ordinária, aqui discutidas, pois a primeira seria formalmente complementar, mas materialmente ordinária, em relação ao dispositivo impugnado (BRASIL, 2008). Portanto, a alteração legislativa teria efeitos jurídicos. Ou seja, a postura do STF foi diametralmente oposta da do STJ ${ }^{4}$.

\footnotetext{
${ }^{3}$ Eis a ementa da decisão, para fins ilustrativos: "Contribuição social sobre o faturamento - COFINS (CF, art. 195, I). 2. Revogação pelo art. 56 da Lei $9.430 / 96$ da isenção concedida às sociedades civis de profissão regulamentada pelo art. $6^{\circ}$, II, da Lei Complementar 70/91. Legitimidade. 3. Inexistência de relação hierárquica entre lei ordinária e lei complementar. Questão exclusivamente constitucional, relacionada à distribuição material entre as espécies legais. Precedentes. 4. A LC 70/91 é apenas formalmente complementar, mas materialmente ordinária, com relação aos dispositivos concernentes à contribuição social por ela instituída. ADC 1, Rel. Moreira Alves, RTJ 156/721. 5. Recurso extraordinário conhecido mas negado provimento".

${ }^{4}$ Vale apontar que julgando a AR 3.761-PR, na sessão de 12/11/2008, a Primeira Seção do STJ deliberou pelo cancelamento da súmula n. 276.
} 
Não é possível negar que com esta virada jurisprudencial as expectativas de muitos interessados foram rompidas, vez que existia a seu favor súmula, precedentes, e jurisprudência do Superior Tribunal de Justiça, o qual tem o dever de uniformizar a interpretação de norma infraconstitucional. Tais expectativas eram legítimas, sem dúvidas, inclusive, devido ao posicionamento e importância da corte no organograma institucional brasileiro. O Ministro Celso de Mello deixa isto claro em seu voto, cujo trecho relevante, transcreve-se:

Essa diretriz jurisprudencial consolidada na Súmula 276/STJ veio a prevalecer no âmbito do Superior Tribunal de Justiça após ampla discussão sobre a controvérsia jurídica em questão.

Esse dado assume, a meu juízo, Senhor Presidente, extrema importância, pois coloca em pauta a questão relevantíssima da segurança jurídica, que há de prevalecer nas relações entre o Estado e o contribuinte, em ordem que as justas expectativas destes não sejam frustradas por atuação inesperada do Poder Público, como sucederia em situações, como a ora em exame, em que se registra clara ruptura de paradigmas, com a prolação de decisão que evidentemente onera a esfera jurídica do sujeito passivo da obrigação tributária.

Não se desconhece que a cláusula constitucional que comtempla o direito à segurança, inclui-se a positivação do direito à segurança jurídica, sob pena de ignorar, com grave lesão aos cidadãos, o atributo da previsibilidade das ações estatais, que norteia e estimula a adoção de padrões de comportamento por parte de pessoas em geral (e dos contribuintes em particular).

Os cidadãos não podem ser vítimas da instabilidade das decisões proferidas pelas instâncias judiciárias ou das deliberações emanadas dos corpos legislativos.

Assume relevo, desse modo, a asserção segundo a qual "o princípio da segurança jurídica supõe o direito seja previsível e que as situações jurídicas permaneçam relativamente estáveis".

A instabilidade das decisões estatais, motivada pela ruptura abrupta de critérios jurisprudenciais que, até então, pautavam o comportamento dos contribuintes - cujo planejamento fiscal na matéria em causa traduzia expressão direta do que continha a súmula $276 / \mathrm{STJ}$-, não pode nem deve afetar ou comprometer a esfera jurídica daquele que, confiando em diretriz firmada pelos Tribunais e agindo de acordo de acordo com esse entendimento, ajustaram de boa-fé, a sua conduta aos pronunciamentos reiterados do Superior Tribunal de Justiça a propósito da subsistência, no caso, da isenção da Cofins (BRASIL, 2008). 
Não está se defendendo aqui que o STF precisa respeitar o posicionamento do STJ, simplesmente pelo entendimento estar pacificado. Isto iria contra a visão hermenêutica do precedente defendida.

O que se está afirmando é que o STF não pode ignorar decisões anteriores acerca do tema, como se estivesse decidindo um tema inovador, jamais debatido, especialmente quando advindo do STJ. Isto gera, também, uma quebra de expectativas bastante relevante. Deve, isso sim, ampliar o debate, discutindo sobre a jurisprudência e os precedentes já firmados, no intuito de exarar uma decisão mais fundamentada o que, no caso, foi feito. É a posição de defendida por Juraci Mourão Lopes Filho (2014, p. 325):

Certamente, pode julgar diferentemente, mas deve considerar, analisar e justificar, confrontando e refutando o posicionamento inferior. Também deve analisar, no corpo do julgado, a guinada jurisprudencial e considerar os efeitos dela. Repita-se: os demais tribunais também compõem o Judiciário, suas manifestações são manifestações de um poder da República. Não é correto exigir que as pessoas devam sempre esperar o posicionamento do Supremo Tribunal Federal para, então, começar a considerar os preceitos judiciais a fim de orientar suas condutas. Isso sequer seria razoável.

A questão da expectativa foi levada em conta, inclusive, quando se discutiu a questão da modulação de efeitos, a qual não foi admitida. Caso fosse, as expectativas seriam ainda mais preservadas, ainda assim, a não admissão não reduz o mérito de ter se debatido tal assunto.

Portanto, a análise de expectativas não pode ser reduzida a simples observância de decisões de graus superiores. Ela deve ser compreendida, também, como a garantia de que as decisões serão mais bem fundamentadas, em virtude de um debate entre as decisões precedentes mais relevantes, sejam elas da mesma corte, ou não, e principalmente de cortes com postura divergente, objetivando, assim, uma decisão mais fundamentada e discutida.

Quanto mais fundamentado for o precedente, menor será o risco de ser desafiado. Uma fundamentação robusta é, inclusive, capaz de convencer os jurisdicionados, de modo que não haverá nem mesmo demandas judiciais contrárias ao entendimento defendido. É o que ocorre quando Amy Barret (2013, p. 1735) afirma que a força de superprecedentes não deriva do grau de deferência devido à corte que o proferiu:

(...) The force of so-called superprecedents, however, does not derive from any decision by the Court about the degree of deference they warrant. 
Indeed, Planned Parenthood of Southeastern Pennsylvania v. Casey shows that the Court is quite incapable of transforming precedent into superprecedent by ipse dixit. The force of these cases derives from the people, who have taken their validity off the Court's agenda. Litigants do not challenge them. If they did, no inferior federal court or state court would take them seriously, at least in the absence of any indicia that the broad consensus supporting a precedent was crumbling (... $)^{5}$

Como consequência de um precedente constantemente fortalecido, o desestímulo à litigância e a ampliação de acordos judiciais serão ainda mais reforçados. Não se trata apenas da questão de reverência hierárquica que estimulará tais resultados, mas também à argumentação jurídica, cada vez mais robusta, acerca dos temas diretamente relacionados aos casos concretos.

\subsection{CELERIDADE PROCESSUAL E ECONOMIA ARGUMENTATIVA}

Outro aspecto que rapidamente é percebido ao tratar da aplicação de precedentes é a possibilidade de ampliar a velocidade dos julgamentos das demandas apresentadas. Com o uso de uma decisão judicial prévia, é possível imbuir de maior celeridade o julgamento da questão discutida.

Esta celeridade pode advir da simples aplicação de um entendimento prévio, por meio de uma citação, afirmando que tal posicionamento é a postura de um tribunal superior. Mas esta não é a melhor forma de realizar a aplicação do precedente, conforme se advoga neste estudo.

É neste ponto que pode surgir uma aparente contradição. A necessidade de argumentar, conforme se defende, consequentemente acarretará um maior esforço jurisdicional, e, por conseguinte, um tempo maior de maturação da decisão judicial. Desta forma, como o precedente permite uma celeridade processual?

Trata-se de uma aparente contradição, repete-se. Não se pode confundir argumentação jurídica, esforço na ampliação do ganho hermenêutico do precedente, e análise

\footnotetext{
5“(...) A força dos chamados superprecedentes, no entanto, não deriva de qualquer decisão do Tribunal sobre o grau de deferência que eles merecem. De fato, Planned Parenthood of Southeastern Pennsylvania v. Casey mostra que o Tribunal é bastante incapaz de transformar em precedente e, superprecedente por ipse dixit. A força desses casos deriva do povo, que tomou sua validade da agenda do Tribunal. Litigantes não os desafiam. Se o fizessem, nenhuma federal court inferior ou state court os levariam a sério, ao menos na ausência de quaisquer indícios de que o amplo consenso apoiando um precedente estava desmoronando (...)". Traduzido pelo autor.
}

Revista Cidadania e Acesso à Justiça | e-ISSN: 2526-026X | Encontro Virtual | v. 6 | n. 2 | p. 18 35 | Jul/Dez. 2020. 
deste, com ausência de fundamentação das decisões judiciais. Quanto menor a fundamentação, menor o tempo gasto para produzir a decisão judicial, seja em qual grau de jurisdição for.

A economia argumentativa se dá pela desnecessidade de repetir toda a construção institucionalmente já realizada. É por isto que "quanto maior for a força hermenêutica de um precedente, maior será a economia” (LOPES FILHO, 2014, p. 375).

Um exemplo brasileiro acerca disto se refere ao reconhecimento da união de pessoas do mesmo sexo. O Supremo Tribunal Federal reconheceu a constitucionalidade da união homoafetiva, ao julgar a ADI n. 4277 e a ADPF n. 132, gerando, assim, um precedente neste sentido. Com isto, diversas ações previdenciárias com o intuito de reconhecer o direito do(a) companheiro(a) à pensões por morte, por exemplo, passaram a ser propostas.

Os tribunais não tem necessidade de, novamente, analisar toda a questão da constitucionalidade da união entre pessoas do mesmo sexo. Podem, assim, analisar a questão jurídica que é levantada, qual seja, a concessão ou não das pensões. Eis o ganho hermenêutico, gerando uma economia argumentativa.

Dois casos podem ilustrar esta situação de forma clara. O primeiro se trata de um julgado do Tribunal de Justiça do Rio Grande do $\mathrm{Sul}^{6}$, em que a corte, de forma unânime, se posicionou acerca da impossibilidade do companheiro do segurado receber o benefício de pensão por morte, vez que não havia comprovação de dependência econômica. Note-se que não houve debate acerca da possibilidade de recebimento de benefício por membro de um casal homoafetivo, pois se reconheceu que esta discussão já havia sido superada pelo STF, no julgamento das ADI n. 4277 e ADPF n. 132 (RIO GRANDE DO SUL, 2011).

A relatora Desembargadora Denise Oliveira Cézar reconheceu este ganho hermenêutico, conforme se observa em seu voto (RIO GRANDE DO SUL, 2011):

\footnotetext{
${ }^{6}$ Para fins ilustrativos, eis a ementa da decisão: "Rio Grande do Sul - Apelação cível. Previdência pública. IPERGS. Benefício de pensão por morte. Companheiro. União estável homoafetiva. Interpretação conforme à constituição. Possibilidade. O companheiro de segurado falecido tem direito à pensão. Inteligência do julgamento de procedência da adi 4277 e da adpf 132 pelo Supremo Tribunal Federal, a fim de dar interpretação conforme à constituição ao art. 1.723 do Código Civil, reconhecendo a proteção jurídica da união estável entre pessoas do mesmo sexo observadas as mesmas regras e consequências da união estável heteroafetiva. Dependência econômica. Prova insuficiente. Inadmissibilidade do pensionamento. Para a concessão do benefício de pensão por morte de segurado do IPERGS aos companheiros, de qualquer gênero, é necessária, além da comprovação da convivência, a da dependência econômica. Caso concreto em que não comprovada a dependência do autor em relação ao segurado. Apelação desprovida. (TJRS, AC 309063-83.2011.8.21.7000, 22 a C. Civ., Rel. Desa. Denise Oliveira Cézar, j. 18/08/2011)”.
} 
Registro que o Supremo Tribunal Federal reconheceu, com efeitos vinculantes, lacuna normativa no ordenamento jurídico pátrio, admitindo, à unanimidade, a união estável homoafetiva como instituto jurídico digno de proteção, como entidade familiar, inclusive previdenciária, ao julgar procedentes a Ação Direta de Inconstitucionalidade n. 4277 e a Arguição de Descumprimento de Preceito Fundamental n. 132, dando ao art. 1.723 do Código Civil "interpretação conforme à Constituição para dele excluir qualquer significado que impeça o reconhecimento da união contínua, pública e duradoura entre pessoas do mesmo sexo como "entidade familiar", entendida esta como sinônimo perfeito de "família". Reconhecimento que é de ser feito segundo as mesmas regras e com as mesmas consequências da união estável heteroafetiva" (grifos do autor).

A segunda decisão é do próprio $\mathrm{STF}^{7}$. Trata-se de caso em que a Caixa de Previdência dos Funcionários do Banco do Brasil interpôs agravo regimental no recurso extraordinário, alegando que a decisão monocrática proferida foi contrária a dispositivos constitucionais. Esta decisão monocrática, por sua vez, havia negado seguimento ao RE interposto em face de acórdão que reconheceu o direito do companheiro do segurado a receber benefícios previdenciários decorrentes de plano de previdência privada (BRASIL, 2012).

Não se rediscutiu o direito do companheiro sobrevivente a receber o benefício previdenciário em questão, em virtude da homoafetividade, pois tal tema já havia sido

\footnotetext{
${ }^{7}$ Eis a ementa da decisão, para fins ilustrativos: "Agravo regimental no recurso extraordinário. Benefício de pensão por morte. União homoafetiva. Legitimidade constitucional do reconhecimento e qualificação da união civil entre pessoas do mesmo sexo como entidade familiar. Possibilidade. Aplicação das regras e consequências jurídicas válidas para a união estável heteroafetiva. Desprovimento do recurso. 1. O Pleno do Supremo Tribunal Federal, no julgamento da ADI 4.277 e da ADPF 132, ambas da Relatoria do Ministro Ayres Britto, Sessão de 05/05/2011, consolidou o entendimento segundo o qual a união entre pessoas do mesmo sexo merece ter a aplicação das mesmas regras e consequências válidas para a união heteroafetiva. 2. Esse entendimento foi formado utilizando-se a técnica de interpretação conforme a Constituição para excluir qualquer significado que impeça o reconhecimento da união contínua, pública e duradoura entre pessoas do mesmo sexo como entidade familiar, entendida esta como sinônimo perfeito de família. Reconhecimento que deve ser feito segundo as mesmas regras e com idênticas consequências da união estável heteroafetiva. 3. O direito do companheiro, na união estável homoafetiva, à percepção do benefício da pensão por morte de seu parceiro restou decidida. No julgamento do RE $n^{\circ}$ 477.554/AgR, da Relatoria do Ministro Celso de Mello, DJe de 26/08/2011, a Segunda Turma desta Corte, enfatizou que "ninguém, absolutamente ninguém, pode ser privado de direitosnem sofrer quaisquer restrições de ordem jurídica por motivo de sua orientação sexual. Os homossexuais, por tal razão, têm direito de receber a igual proteção tanto das leis quanto do sistema político-jurídico instituído pela Constituição da República, mostrando-se arbitrário e inaceitável qualquer estatuto que puna, que exclua, que discrimine, que fomente a intolerância, que estimule o desrespeito e que desiguale as pessoas em razão de sua orientação sexual. (...) A família resultante da união homoafetiva não pode sofrer discriminação, cabendo-lhe os mesmos direitos, prerrogativas, benefícios e obrigações que se mostrem acessíveis a parceiros de sexo distinto que integrem uniões heteroafetivas". (Precedentes: RE n. 552.802, Relator o Ministro Dias Toffoli, DJe de 24.10.11; RE n. 643.229, Relator o Ministro Luiz Fux, DJe de 08.09.11; RE n. 607.182, Relator o Ministro Ricardo Lewandowski, DJe de 15.08.11; RE n. 590.989, Relatora a Ministra Cármen Lúcia, DJe de 24.06.11; RE n. 437.100, Relator o Ministro Gilmar Mendes, DJe de 26.05.11, entre outros). 4. Agravo regimental a que se nega provimento. (STF, Ag. Reg. no RE 687.432, Rel. Min. Luiz Fux, j. 18/09/2012)”.
}

Revista Cidadania e Acesso à Justiça | e-ISSN: 2526-026X | Encontro Virtual | v. 6 | n. 2 | p. 18 35 | Jul/Dez. 2020. 
debatido e superado nos casos paradigmas anteriores, razão pela qual o recurso de agravo regimental teve seu provimento negado, unanimemente. O relator Ministro Luiz Fux fundamentou sua decisão em precedentes judiciais, reconhecendo sua importância para o ganho hermenêutico de casos futuros e a consequente celeridade advinda de sua utilização (BRASIL, 2012).

In casu, a Turma Julgadora não divergiu do entendimento que se pacificou nesta Corte, ao julgar-se a ADI 4.277 e a ADPF 132, ambas da Relatoria do Ministro Ayres Britto, Sessão de 05/05/2011, onde se fixou que o preceito constante do art. 1.723 do Código Civil - "é reconhecida como entidade familiar a união estável entre o homem e a mulher, configurada na convivência pública, contínua e duradoura e estabelecida com o objetivo de constituição de família" - não obsta que a união de pessoas do mesmo sexo possa ser reconhecida como entidade familiar apta a merecer proteção estatal.

Anote-se, que neste julgamento, deu-se interpretação conforme a Constituição para excluir qualquer significado que impeça o reconhecimento da união contínua, pública e duradoura entre pessoas do mesmo sexo como entidade familiar, entendida esta como sinônimo perfeito de família. Reconhecimento este, que deve ser feito segundo as mesmas regras e com idênticas consequências da união estável heteroafetiva (grifos do autor).

Não se pode olvidar, e isso precisa ficar claro, que as uniões tratadas pelo STF e pelos tribunais que buscam a aplicação do precedente, não podem possuir disparidades substanciais. Por isto que é necessária a análise do caso concreto, e não mera citação de decisões passadas. Caso haja diferença contundente nas questões tratadas, o precedente não é aplicável.

Desta forma, aprofundar a discussão acerca do conteúdo de um precedente, se em um primeiro momento requer um esforço maior, posteriormente significa uma maior economia argumentativa e celeridade no julgamento da demanda. E tão importante quanto, uma decisão judicial cada vez mais fundamentada. A razoável duração do processo não pode ser buscada apenas através de uma rápida solução de um caso, mas mediante uma solução célere e de qualidade. E para tal, o precedente judicial precisa ser bem construído e aplicado.

\section{CONSIDERAÇÕES FINAIS}

Após o presente estudo, é possível afirmar que o uso dos precedentes judicias é uma realidade no sistema brasileiro e que tem potencial para ampliar o acesso à ordem jurídica 
justa. Diversos são os entraves para tal, é verdade: os custos do processo, a demora excessiva para o julgamento dos conflitos, as disparidades entre os litigantes eventuais e habituais, bem como a grande quantidade de causas que tramitam no Judiciário.

Nesta toada os precedentes judiciais vem sendo incluídos e fortalecidos no nosso sistema jurídico, com destaque para o CPC de 2015, o qual trouxe de forma explícita preocupação com o tema.

Desta forma se trouxe seis argumentos favoráveis ao uso dos precedentes judiciais, inclusive no Brasil, quais sejam: segurança jurídica, igualdade, coerência, definição de expectativas, celeridade processual e economia argumentativa.

Cada um destes argumentos foi aprofundado e analisado, de modo a se concluir que caso os precedentes sejam bem manejados, ou seja, não levando em consideração apenas a sua aplicação com base na autoridade do órgão criador, mas também no potencial hermenêutico desta fonte do direito, é possível superar a chamada "Crise do Judiciário", materializando na prática todos os argumentos apontados, e alcançando um efetivo acesso À justiça.

\section{REFERÊNCIAS}

ARAÚJO, José Henrique Mouta. O devido processo legal e a coletivização dos conflitos. In. DIAS, Jean Carlos; KLAUTAU FILHO, Paulo (coord.). O devido processo legal. São Paulo: Método, 2010.

BARRET, Amy Connet. Precedent and jurisprudential disagreement. Texas Law Review, vol. 91:1711. Disponível em: 〈http://home.heinonline.org/>. Acesso em: 25 set. 2020.

BASTOS, Antônio Adonias Aguiar. Devido processo legal nas demandas repetitivas. Tese (Doutorado em Direito). Universidade Federal da Bahia - UFBA, Salvador, 2012.

BRASIL, Constituição da República Federativa do Brasil. Promulgada em 05 de outubro de 1988. Disponível em: <http://www.planalto.gov.br/>. Acesso em: 25 set. 2020.

Supremo Tribunal Federal. RE. n. 377.457/2008, Relator: Ministro Gilmar Mendes;

Data de julgamento: 17.09.2008, Tribunal pleno, Data de publicação: 19.12.2008; 2008.

Disponível em:

$<$ http://redir.stf.jus.br/paginadorpub/paginador.jsp?docTP=AC\&docID=570335>. Acesso em: 25 set. 2020.

Revista Cidadania e Acesso à Justiça | e-ISSN: 2526-026X | Encontro Virtual | v. 6 | n. 2 | p. 18 35 | Jul/Dez. 2020. 
Supremo Tribunal Federal. Ag. Reg. no RE 687.432, Relator: Ministro Luiz Fux; Data de julgamento: 18/09/2012, Data de publicação: 02.10.2012. Disponível em: $<$ http://redir.stf.jus.br/paginadorpub/paginador.jsp?docTP=TP\&docID=2857867>. Acesso em: 25 set. 2020 .

CAPPELLETTI, Mauro; GARTH, Bryant. Acesso à justiça. Tradução por Ellen Gracie Northfleet. Porto Alegre: S. A. Fabris, 2002.

CHE, Yeon-Koo; YI, Jong Goo. The Role of Precedents in Repeated Litigation. The Journal of Law, Economics, \& Organization, v.9, n.2, 1993. Disponível em:

<http://www.columbia.edu/ yc2271/files/papers/precedents.pdf>. Acesso em: 25 set. 2020.

DIAS, Jean Carlos. Análise econômica do processo civil brasileiro. São Paulo: Método, 2009.

LOPES FILHO, Juraci Mourão. Os precedentes judiciais no constitucionalismo brasileiro contemporâneo. Salvador: JusPODIVM, 2014.

MARINONI, Luiz Guilherme. Precedentes obrigatórios. 2. ed. São Paulo: Revista dos Tribunais, 2011.

PEREIRA, Bernardo Augusto da Costa. Os precedentes judiciais e a razoável duração do processo: uma análise a partir da teoria do direito como integridade de Ronald Dworkin. Rio de Janeiro: Lumen Juris, 2017.

RIO GRANDE DO SUL. Tribunal de Justiça do Rio Grande do Sul. AC n. 30906383.2011.8.21.7000, Data de julgamento: 18.08.2011. Relatora Desembargadora Denise Oliveira César, 22a Câmara Cível. Disponível em: <https://www.tjrs.jus.br/>. Acesso em: 25 set. 2020. 